Skin

Appendage

Disorders
Skin Appendage Disord 2018;4:34-36

DOI: 10.1159/000478053
Received: April 26, 2017

Accepted: June 6, 2017

Published online: July 20, 2017

\title{
Impact of Folliculitis Decalvans on Quality of Life and Subjective Perception of Disease
}

\author{
Cristina Pindado-Ortega ${ }^{a}$ David Saceda-Corralo ${ }^{a} \quad$ Laura Miguel-Gómez $^{a}$ \\ Diego Buendía-Castaño ${ }^{a}$ Pablo Fernández-González ${ }^{a}$ \\ Oscar M. Moreno-Arrones ${ }^{a}$ Pablo Fonda-Pascuala ${ }^{a}$ Adrian Alegre-Sánchez $^{a}$ \\ Rita Rodrigues-Barata ${ }^{a}$ Sergio Vañó-Galván ${ }^{a, b}$ \\ ${ }^{a}$ Dermatology Department, University Hospital Ramon y Cajal, and ' University of Alcalá, Madrid, Spain
}

\section{Established Facts}

- Alopecia may have a negative impact on quality of life. There are no studies regarding quality of life exclusively in patients with folliculitis decalvans.

\section{Novel Insights}

- Patients with folliculitis decalvans suffer from a mild to moderate decrease in their quality of life.

\section{Keywords}

Trichology · Cicatricial alopecia · Alopecia $\cdot$ Hair $\cdot$ Hair loss Psychodermatology

\begin{abstract}
Folliculitis decalvans (FD) is a primary neutrophilic scarring alopecia characterized by perifollicular papules, crusts, and pustules frequently located on the vertex. FD may affect young men and women. Since it may lead to hair loss, it can have a negative impact on patients' quality of life. Nevertheless, studies have focused on clinical, prognostic, and therapeutic aspects without considering the psychological impact of FD. In our study, we found that FD patients experienced a considerable impact on their quality of life.
\end{abstract}

๑ 2017 S. Karger AG, Basel

E-Mail karger@karger.com

www.karger.com/sad
Interestingly, almost half of the patients considered that their alopecia was related to a poor medical care in their past. To our knowledge, this is the first description of the impact of FD on patients' quality of life, and it highlights the importance of psychological support for these patients.

(C) 2017 S. Karger AG, Basel

\section{Introduction}

Alopecia may have a negative impact on quality of life (QoL) since hair loss modifies patients' physical appearance and self-image, which consequently may lead to a loss of confidence and low self-esteem [1]. To our knowledge, there are no studies regarding QoL exclusively in

Cristina Pindado-Ortega, MD

Dermatology Department, University Hospital Ramon y Cajal

Carretera Colmenar Viejo km 9.100

ES-28034 Madrid (Spain)

E-Mail cpindadoortega@gmail.com 
Table 1. Clinical and demographic characteristics of 52 patients with folliculitis decalvans

\begin{tabular}{ll}
\hline Clinical characteristics & $n(\%)$ \\
\hline Gender & \\
$\quad$ Male & $29(55.8)$ \\
$\quad$ Female & $23(44.2)$ \\
Age & $23(44.2)$ \\
$\quad 23-40$ years & $22(42.3)$ \\
$\quad 41-60$ years & $7(13.5)$ \\
$61-80$ years & $11(21.2)$ \\
Grade $(n=46)$ & $17(32.7)$ \\
I $(<2 \mathrm{~cm})$ & $18(34.6)$ \\
II $(2-4.99 \mathrm{~cm})$ & \\
III $(>5 \mathrm{~cm})$ &
\end{tabular}

patients with folliculitis decalvans (FD). The objective of our study was to describe the impact of FD on the QoL, psychological alterations, and perception of disease in a large series of patients with FD.

\section{Materials and Methods}

A descriptive cross-sectional study was performed including patients clinically diagnosed with FD. FD severity was classified into 3 grades according to the scale of Vañó-Galván et al. [2]. We used the Spanish version of validated questionnaires to measure dermatology-specific QoL (Dermatology Life Quality Index: DLQI), health-related QoL (Short Form 12 Health Survey version II: SF-12), and perception of disease (Revised Illness Perception Questionnaire: IPQ-R) [3-5]. The Pearson correlation coefficient was used to analyze the correlation between the scores.

\section{Results}

A total of 52 patients (Table 1) completed at least 1 questionnaire. The DLQI $(n=52)$ showed a slight impairment of QoL (total DLQI $=4.48$ ). However, $9.6 \%$ of patients with FD presented a serious impairment of QoL (DLQI $\geq 11$ ) related to alopecia (Table 2 ) $[6,7]$. Regarding SF-12 $(n=48)$, there were no significant differences between the overall median score for the physical component summary $(52.14 \pm 8.93)$ compared to the overall mental component summary $(49.25 \pm 9.16)$. A subgroup of 18 patients completed the IPQ-R questionnaire, revealing that patients perceived FD as a chronic disease (IPQ$\mathrm{R}$ timeline, $19.68 \pm 9.42)$, and they believed that they could control their illness with medical treatment (IPQ-R

Quality of Life in Folliculitis Decalvans
Table 2. Comparison of Dermatology Quality of Life Index (DLQI) scores in patients with folliculitis decalvans (FD), primary cicatricial alopecia (PCA), and alopecia areata (AA)

\begin{tabular}{lcll}
\hline DLQI & $\begin{array}{l}\text { FD, } \\
n(\%)\end{array}$ & $\begin{array}{l}\text { PCA, } \\
n(\%)[6]\end{array}$ & $\begin{array}{l}\text { AA, } \\
n(\%)[7]\end{array}$ \\
\hline $0-1$ (no effect) & $10(19.2)$ & $19(21)$ & $183(26.2)$ \\
$2-5$ (small effect) & $31(59.6)$ & $38(41)$ & $229(32.8)$ \\
6-10 (moderate effect) & $6(11.5)$ & $19(21)$ & $152(21.8)$ \\
$\begin{array}{l}11-20 \text { (very large effect) } \\
\text { 21-30 (extremely large } \\
\text { effect) }\end{array}$ & $4(7.7)$ & $12(13)$ & $119(17.0)$ \\
\hline Total & $1(1.9)$ & $4(4)$ & $15(2.1)$ \\
\hline
\end{tabular}

treatment control, $12.84 \pm 7.09)$. The degree of understanding of the disease was relatively high (IPQ-R illness coherence, $13.10 \pm 7.63$ ). Regarding the explanations that patients considered to be related to the course of their alopecia, the causes with the highest agreement were a bacterium or virus (46.7\%), stress or worries (46.7\%), and poor medical care in their past (46.6\%). Rates of the DLQI and IPQ-R were correlated with demographic variables. There was a positive correlation between total DLQI and emotional representations $(r=0.63, p<0.01)$. A significant association was established between the degree of the disease and perceived consequences of living with $\mathrm{FD}$ $(r=0.656, p<0.05)$ and emotional representations $(r=$ $0.577, p<0.05)$. There was no statistically significant difference in the impairment of QoL based on age, gender, or severity.

\section{Discussion}

A negative impact of FD on QoL may be observed, although the severity of the disease is not associated with it, which is congruent with previous findings in other alopecias [6]. Interestingly, FD patients associate their alopecia with a poor medical care in their past, but they still believe that medical treatment can control the disease. Considering the multiple choices of treatment available for FD [2], we must provide the best option to each patient.

This study had potential limitations. This is a crosssectional study in which questionnaires were administered at different stages of the disease in each patient. Furthermore, a mental health history was not assessed. Additionally, activity of FD and scalp location of the hair loss

Skin Appendage Disord 2018;4:34-36 DOI: $10.1159 / 000478053$ 
might play a role in the results obtained. Nevertheless, despite these potential limitations, the presented results are relevant to show the impact of FD on QoL.

\section{Conclusion}

Our findings showed that most FD patients suffered from a mild to moderate decrease in their QoL that limited their emotional well-being. Management of patients with FD should include a psychological approach, providing psychological support if required.

\section{Statement of Ethics}

Informed consent was obtained from the patients described in this article. All human and animal studies are approved by an Institutional Review Board.

\section{Disclosure Statement}

The authors have no conflicts of interest to declare. This article has no funding source.

\section{References}

1 Hunt N, McHale S: The psychological impact of alopecia. BMJ 2005;331:951-953.

2 Vañó-Galván S, Molina-Ruiz AM, Fernández-Crehuet P, Rodrigues-Barata AR, AriasSantiago S, Serrano-Falcón C, et al: Folliculitis decalvans: a multicentre review of 82 patients. J Eur Acad Dermatol Venereol 2015;29:17501757.

3 de Tiedra AG, Mercadal J, Badía X, Mascaró $J M$, Herdman M, et al: Adaptación transcultural al español del cuestionario Dermatology Life Quality Index (DLQI): El Îndice de Cali- dad de Vida en Dermatología. Actas Dermosifiliogr 1998;89:692-700.

4 Monteagudo Piqueras O, Hernando Arizaleta L, Palomar Rodríguez JA: Normas poblacionales de referencia de la versión española del SF-12V2 para la Región de Murcia. Gac Sanit 2011;25:50-61.

5 Pacheco-Huergo V, Viladrich C, Pujol-Ribera E, Cabezas-Peña C, Núñez M, Roura-Olmeda $\mathrm{P}$, et al: Percepción en enfermedades crónicas: validación lingüística del Illness Perception Questionnaire Revised y del Brief
Illness Perception Questionnaire para la población española. Aten Primaria 2012;44: 280-287.

6 Chiang YZ, Bundy C, Griffiths CEM, Paus R, Harries MJ: The role of beliefs: lessons from a pilot study on illness perception, psychological distress and quality of life in patients with primary cicatricial alopecia. Br J Dermatol 2015;172:130-137.

7 Qi S, Xu F, Sheng Y, Yang Q: Assessing quality of life in alopecia areata patients in China. Psychol Health Med 2015;20:97-102. 